\title{
Pendampingan Penilaian Mandiri Bangunan Sekolah Muhammadiyah Aman Gempa Bumi Di Yogyakarta
}

\author{
Sri Atmaja P. Rosyidi', As'at Pujianto', Yoga A. Harsoyo, Surya Budi Lesmana', \\ Arwan Suryanto ${ }^{2}$, Restu Faizah', Budi Santoso ${ }^{3}$ \\ 1. Teknik Sipil, Fakutas Teknik, Universitas Muhammadiyah Yogyakarta, Yogyakarta \\ PUSPER, Universitas Muhammadiyah Yogyakarta, Yogyakarta \\ Muhammadiyah Disaster Management Center, Indonesia \\ Email: atmaja_sri@umy.ac.id \\ DOI: $10.18196 / p p m .36 .328$
}

\begin{abstract}
Abstrak
Sejalan dengan semangat untuk melindungi hak-hak anak atas perlindungan, keamanan, dan kelangsungan hidup, Pemerintah telah menerbitkan Perka BNPB No. 4 tahun 2012 tentang Pedoman Penerapan Sekolah Aman Bencana terhadap Kerangka Kerja Sekolah Aman yaitu fasilitas sekolah aman, manajemen bencana di sekolah dan pendidikan pencegahan dan pengurangan risiko bencana. MDMC dan Majelis Dikdasmen Muhammadiyah sudah menerapkan konsep-konsep dan implementasi sekolah siaga bencana di sekolah-sekolah Muhammadiyah dengan membentuk Sistem Pendidikan Aman Bencana (SPAB). Namun, MDMC dan Majelis dikdasmen PMW DIY masih memerlukan tindak lanjut yang berkaitan dengan penilaian bangunan sekolah Muhammadiyah aman bencana dari sisi struktural, yaitu bagaimana sekolah diberdayakan untuk mampu menilai secara mandiri kondisi bangunan yang aman terhadap gempa bumi untuk langkah mitigasi yang sesuai. Penguatan kapasitas sekolah dilakukan dengan pendampingan dan FGD melalui webinar yang dilaksanakan dengan tiga tahapan, yaitu pengenalan dasar-dasar kebencanaan, penilaian bangunan untuk sekolah aman bencana dan praktek pelaksanaan penilaian bangunan sekolah secara mandiri. Luaran kegiatan ini adaah terususnya pedoman penilaian sekolah aman bencana a lam gempa bumi dan tindak lanjut dengan penyusunan tim evaluator sekolah aman dari MDMC, Majelis Dikdasmen dan tim penilai bangunan yang ditunjuk dari masing-masing sekolah Muhammadiyah di wilayah DIY.
\end{abstract}

Kata Kunci : sekolah aman, gempa bumi, mitigasi bencana, pemberdayaan sekolah

\section{Pendahuluan}

Indonesia merupakan salah satu negara yang memiliki wilayah yang rentan terhadap bencana termasuk gempa dan tsunami (Rosyidi, 2008). Salah satu dampak dari gempa dan tsunami yang terjadi di Indonesia adalah kerusakan sarana dan prasarana bangunan (Pujianto et al., 2019), termasuk bangunan sekolah, yang mengakibatkan terganggunya proses pembelajaran siswa di sekolah. Lebih dari 7.000 sekolah rusak berat akibat gempa dan tsunami sejak tahun 2004. Dampak tersebut akan lebih parah jika bencana terjadi pada saat proses belajar-mengajar sedang berlangsung di sekolah, karena reruntuhan bangunan dan benda sekitarnya dapat menimpa dan atau menimbun peserta didik, guru maupun tenaga kependidikan lainnya. Oleh karena itu, diperlukan sekolah yang dapat menjamin keamanan dan keselamatan warga sekolah siaga setiap saat termasuk dari ancaman bencana alam.

Sejalan dengan semangat untuk melindungi hak-hak anak atas perlindungan, keamanan, dan kelangsungan hidup dan juga hak untuk mendapatkan pendidikan dasar yang berkualitas dan berkesinambungan, Pemerintah telah menerbitkan Perka BNPB No. 4 tahun 2012 tentang Pedoman Penerapan Sekolah/Madrasah Aman Bencana terhadap Kerangka Kerja Sekolah Aman yang Komprehensif, di mana Kerangka Kerja ini dengan tiga pilarnya sudah disepakati oleh dunia 
internasional, khususnya UNISDR sebagai Badan PBB bidang Pengurangan Risiko Bencana. Penelaahan materi yang berasal dari berbagai sumber, baik dari Kementerian/ Lembaga (Kementerian Pendidikan dan Kebudayaan, BNPB, dan Kementerian Pekerjaan Umum dan Perumahan Rakyat /PUPR), organisasi/ lembaga (ChildFund, HOPE worldwide Indonesia, INEE, Konsorsium Pendidikan Bencana, MDMC, Plan Indonesia, Save the Children, World Bank, dan World Vision), serta lembaga PBB (UNDP - SCDRR Project, UNESCO, UNICEF , dan UNOCHA) telah menghasilkan modul yang mengacu pada Kerangka Kerja Sekolah Aman yang Komprehensif, yaitu:

- Modul 1 - Pilar 1: Fasilitas Sekolah Aman

- Modul 2 - Pilar 2: Manajemen Bencana di Sekolah

- Modul 3 - Pilar 3: Pendidikan Pencegahan dan Pengurangan Risiko Bencana

Muhammadiyah Disaster Management Center (MDMC) sudah menerapkan sekolah siaga bencana. Semakin gencar usai gempa Yogyakarta dan Jawa Tengah di sekolah-sekolah Muhammadiyah. MDMC PP Muhammadiyah terus meneguhkan komitmen dalam pendidikan bencana. Salah satunya dengan mendorong pembentukan Sekretariat Daerah (Sekda) Sistem Pendidikan Aman Bencana (SPAB). Selain itu, sejak 2010, MDMC telah rutin mengirimkan wakilwakilnya dalam Konsorsium Pendidikan Bencana Indonesia (KPBI). Semua itu dilakukan tidak lain demi mewujudkan betul internasilisasi nilai-nilai dalam pendidikan bencana. Namun, MDMC masih memerlukan tindak lanjut yang berkaitan dengan penilaian bangunan sekolah Muhammadiyah aman bencana dari sisi struktural. Menyusun pedoman penilaian sekolah aman bencana alam gempa bumi sebagai dasar penentuan kriteria bagi langkah mitigasi yang sesuai.

Tujuan dari kegiatan pengabdian kepada masyarakat ini adalah melakukan pendampingan dalam penyusunan pedoman penilaian mandiri sekolah aman bencana alam gempa bumi yang dapat digunakan oleh MDMC dan Majelis Pendidikan Dasar dan Menengah Pimpinan Wilayah Muhammadiyah (Dikdasmen PWM) DIY untuk diterapkan dalam melakukan langkah mitigasi pemetaan sekolah-sekolah Muhammadiyah di Yogyakarta. Selanjutnya, dilakukan pendampingan dan sosialisasi panduan serta materi kebencanaan gempa dan dampaknya kepada bangunan sekolah kepada tim evaluator sekolah aman dari MDMC PP Muhammadiyah, Majelis Dikdasmen PWM DIY dan tim penilai bangunan yang ditunjuk dari masing-masing sekolah Muhammadiyah di wilayah DIY guna peningkatan kapasitas dan pemberdayaan. Pemberdayaan dilaksanakan secara daring (online) melalui seri webinar dan diakhiri dengan webinar pendampingan penilaian sekolah yang ditunjuk untuk memperdalam materi penilaian sekolah aman.

\section{Metode Pelaksanaan}

Kegiatan pengabdian masyarakat untuk pendampingan penyusunan penilaian bangunan Sekolah Muhammadiyah aman gempa bumi ini dilaksanakan melalui tiga rangkaian tahapan yang dilakukan dari bulan April hingga Oktober 2020. Sasaran dari kegiatan ini adalah stakeholder (pemangku kebijakan) dalam melakukan penilaian sekolah aman gempa, yaitu tim evaluator sekolah aman dari MDMC PP Muhammadiyah, Majelis Dikdasmen PWM DIY dan tim penilai bangunan yang ditunjuk dari masing-masing sekolah Muhammadiyah di wilayah DIY. Harapannya 
pemangku kebijakan di Sekolah Muhammadiyah dapat melakukan penilaian mandiri pada bangunan sekolah Muhammadiyah. Tahapan pelaksanaan kegiatan pengabdian masyarakat ini dijelaskan dalam began alir berikut ini (Gambar 1).

Kegiatan ini dimulai dari tahapan pertama yaitu perencanaan kegiatan dan perumusan melalui focus group discussion (FGD) MDMC PP Muhammadiyah khususnya dengan Divisi Pengurangan Risiko Bencana dan Satuan Pendidikan Aman Bencana. Selanjutnya, dari hasil FGD dilakukan tindak lanjut dengan menyusun tim perumus penilaian bangunan sekolah aman gempa bumi yang terdiri dari staf pengajar di Program Studi Teknik Sipil UMY dan praktisi arsitektur dari PUSPER UMY. Tim yang dibentuk seterusnya menyusun bahasan dan topik penilaian yang akan dimasukkan dalam pedoman, yang berhubungan dengan bagian struktur dan arsitektur bangunan sekolah yang perlu mendapatkan perhatian dan penilaian yang memiliki kerentanan apabila terjadi gempa bumi. Setelah pedoman disiapkan, dilaksanakan simulasi dengan peninjauan bangunan dan praktik penilaian pedoman oleh tim. Diadakannya evaluasi peninjauan ke bangunan sekolah, kemudian dilakukan pengkajian kembali untuk finalisasi penyusunan formulir penilaian dan kriteria penilaian bangunan sekolah yang aman gempa bumi. Evaluasi terhadap pedoman bangunan sekolah dilakukan melalui indeks penilaian bangunan disepakati oleh tim.

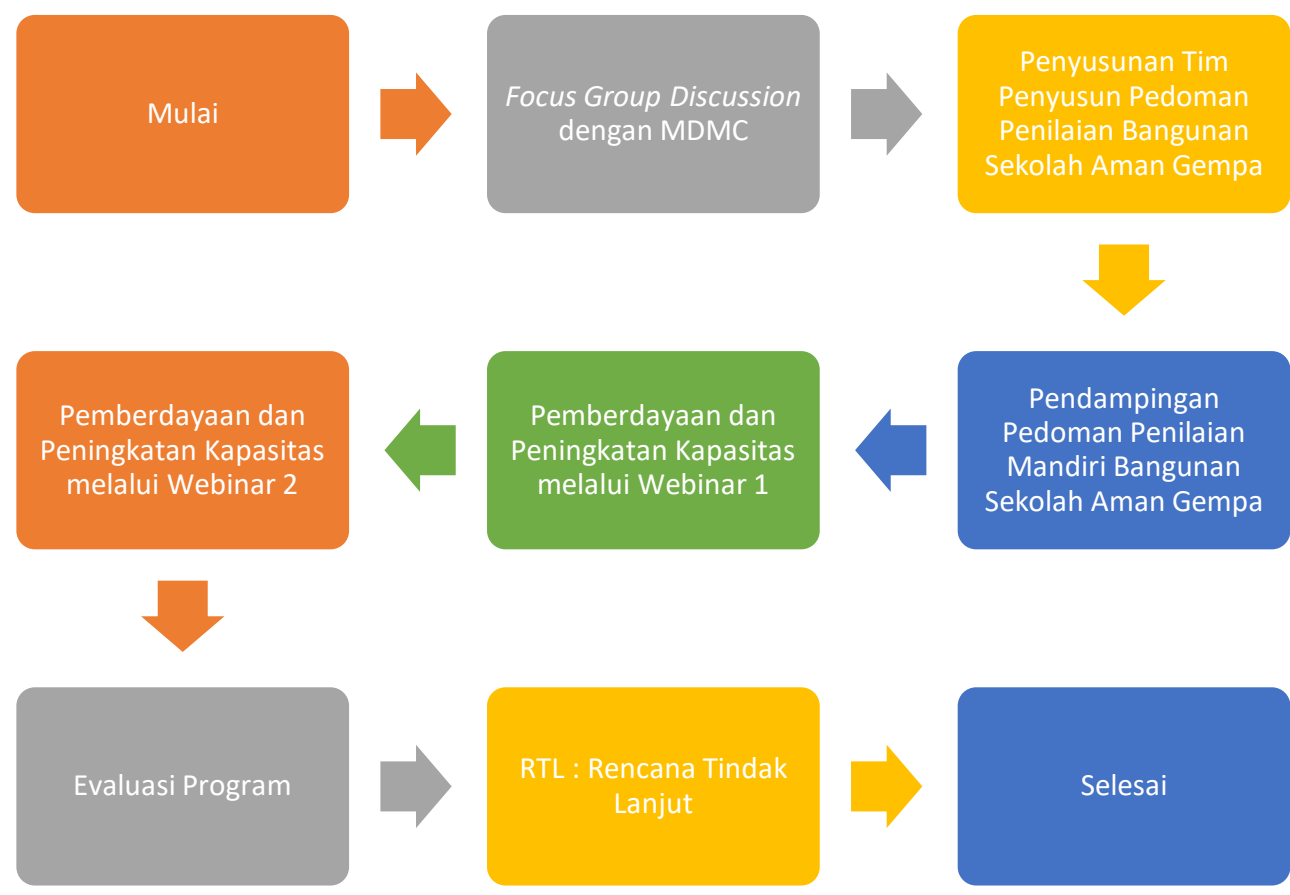

Gambar 1. Bagan alur tahapan pelaksanaan kegiatan pengabdian masyarakat pedampingan pedoman penilaian mandiri bangunan sekolah aman gempa

Tahapan selanjutnya adalah pendampingan kepada untuk tim evaluator sekolah aman dari MDMC PP Muhammadiyah, Majelis Dikdasmen PWM DIY dan tim penilai bangunan yang ditunjuk dari masing-masing sekolah Muhammadiyah di wilayah DIY melalui webinar yang 
dijalankan sebanyak 2 sesi. Webinar tersebut dimaksudkan untuk menyampaikan alasan dibuatnya sebuah modul kriteria penilaian bangunan sekolah aman gempa dan penjelasan konsep penilaian yang ada didalamya. Webinar pertama berisi tentang pengenalan mengenai sekolah aman bencana dan konspe penilaian bangunan sekolah termasuk didalamnya dijelaskan beberapa macam risiko dan kerentanan bangunan akibat adanya gempa bumi pada struktur bangunan atas dan struktur bangunan bawah. Webinar kedua berisi pendampingan materi sebab akibat terjadinya gempa bumi dan cara penanggulangannya, serta kriteria pelaksanaan pembangunan gedung sekolah dari sisi biaya, lingkup, waktu pengerjaan, yang semuanya harus sesuai dengan kualitas bahan bangunannya dan dikerjakan oleh orang yang memang ahli di bidangnya. Selain itu dalam dalam perencanaan, bangunan sekolah harus memperhitungkan beban yang akan ditanggung dan dimensi struktur harus diperhitungkan terlebih dahulu sesuai dengan kriteria pembebanan.

Tahapan terakhir adalah evaluasi program dan rencana tindak lanjut. Tahapan evaluasi dan penyusunan RTL dilakukan melalui diskusi daring dengan MDMC PP Muhammadiyah.

\section{Hasil dan Pembahasan}

Kegiatan pengabdian ini telah menyelesaikan seluruh rencana tahapan yang dengan melakukan efisiensi dan akselerasi kegiatan mengingat kondisi pandemi yang menyebabkan kegiatan terkendala dalam pelaksanaannya. Pedoman penilaian dan evaluasi bangunan sendiri yang menjadi materi utama dalam kegiatan ini terdiri dari tiga tahapan. Pada tahap pertama penyusunan pedoman ini, dilakukan proses identifikasi bangunan sekolah yang memenuhi ketentuan standar ini dengan cepat yang berpedoman pada ASCE 41-13. Pada tahapan kedua dan ketiga, pedoman yang dihasilkan dari tahapan pertama dilakukan evaluasi dan penyederhanaan dengan memasukkan kriteria bangunan sekolah aman, kondisi bangunan sekolah yang ada, penerapan standar bangunan yang berlaku di Indonesia dan memperhatikan aspek keamanan bangunan dan pengelolaan infrastruktur (Hudson, et al. 1997). Manfaat penyusunan pedoman ini langsung dapat diterima oleh MDMC untuk melaksanakan kegiatan pengurangan risiko bencana dan bagi Majelis Dikdasmen PWM dan pengelola sekolah untuk dapat memberikan penilaian cepat dan visul dari bangunan sekolah yang ada dan pemetaan kerentanan sekolah terhadap bencana gempa bumi di wilayah Yogyakarta. Adapun ringkasan hasil kegiatan dan evaluasinya diberikan dalam tabel berikut ini di bawah.

\begin{tabular}{|c|c|c|c|c|c|c|c|c|c|c|c|c|}
\hline \multirow{3}{*}{ No } & \multicolumn{12}{|c|}{ Hasil kegiatan dan evaluasi } \\
\hline & \multirow{2}{*}{ Nama Kegiatan } & \multicolumn{10}{|c|}{ Bulan } & \multirow{2}{*}{ Evaluasi dan Hasil Pelaksanaan } \\
\hline & & 3 & 4 & 5 & 6 & 7 & 8 & 9 & 10 & 11 & 12 & \\
\hline 1 & $\begin{array}{l}\text { Perencanaan kegiatan } \\
\text { dan perumusan }\end{array}$ & & & & & & & & & & & $\begin{array}{l}\text { Telah terlaksana di bulan Februari } \\
\text { dan Maret }\end{array}$ \\
\hline 2 & $\begin{array}{l}\text { Peninjauan lokasi } \\
\text { kegiatan }\end{array}$ & & & & & & & & & & & $\begin{array}{l}\text { Kegiatan tertunda karena pandemi } \\
\text { COVID dan akan dilaksanakan } \\
\text { kembali pada bulan Agustus } 2020 \\
\text { bersamaan dengan pendampingan } \\
\text { survei lapangan }\end{array}$ \\
\hline 3 & $\begin{array}{l}\text { Penyusunan formulir } \\
\text { kriteria penilaian } \\
\text { bangunan }\end{array}$ & & & & & & & & & & & Telah terlaksana \\
\hline 4 & Survei lapangan & & & & & & & & & & & $\begin{array}{l}\text { Kegiatan tertunda karena pandemi } \\
\text { COVID dan dilaksanakan kembal } \\
\text { pada bulan Agustus ini bersamaan } \\
\text { dengan pendampingan survei } \\
\text { lapangan }\end{array}$ \\
\hline 5 & Penyusunan evaluasi & & & & & & & & & & & Telah terlaksana \\
\hline
\end{tabular}




\begin{tabular}{llc}
\hline 6 & $\begin{array}{l}\text { Penilaian } \\
\text { indeks }\end{array}$ & Telah terlaksana \\
\hline 7 & Penyusunan pedoman & Telah terlaksana \\
\hline
\end{tabular}

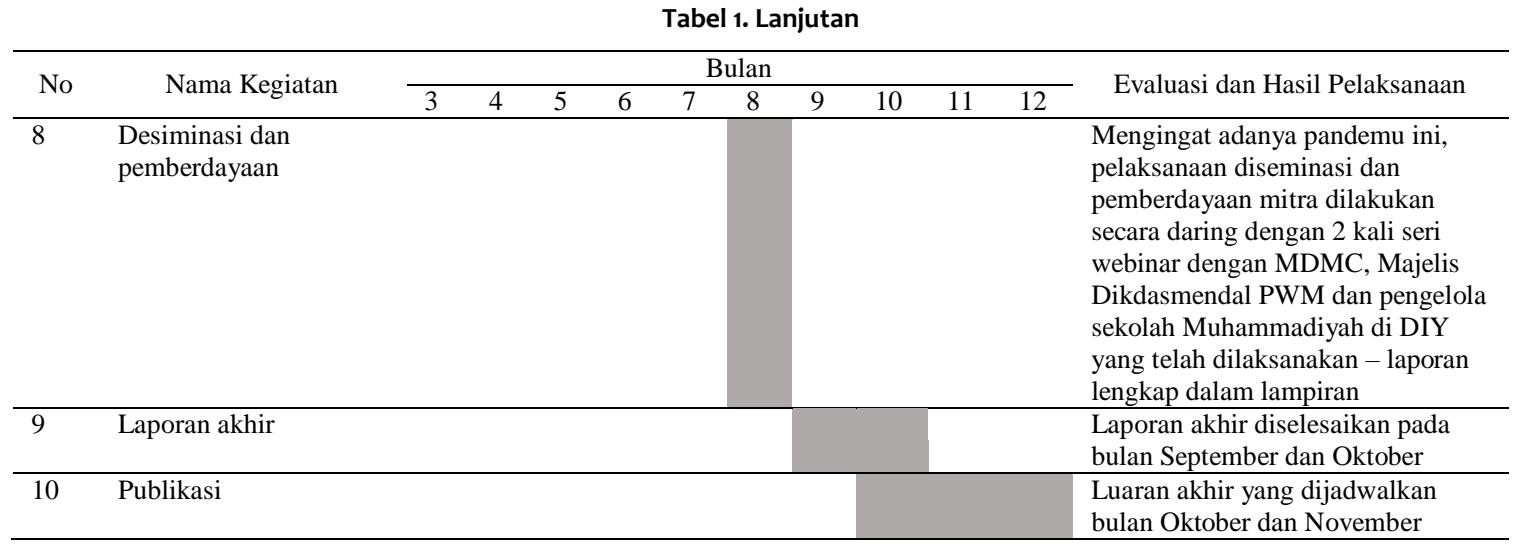

Pelaksanaan pendamping terhadap tim evaluator sekolah aman dari MDMC PP Muhammadiyah, Majelis Dikdasmen PWM DIY dan tim penilai bangunan yang ditunjuk dari masing-masing sekolah Muhammadiyah di wilayah DIY selanjutnya dilakukan secara daring mengingat kondisi pandemi COVID-19 yang masih berlangsung di Indonesia. Adapun kegiatan pendampingan melalui webinar dilaksanakan dengan materi pendampingan sebagaimana dijelaskan berikut ini.

WEBINAR CAPACITY BUILDING SERI 1: FOCUS GROUP DISCUSSION (FGD) PENILAIAN MANDIRI BANGUNAN SEKOLAH AMAN GEMPA, UMY - MDMC

Kerjasama MDMC PP Muhammadiyah dan Prodi Teknik Sipil, Universitas Muhammadiyah Yogyakarta untuk Penyusunan Modul Penilaian Mandiri Bangunan Sekolah Aman Gempa

WAKTU: RABU, 5 Agustus 2020, Waktu: 19.00 - 21.00 WIB

RUNDOWN:

1. "Pengantar: MDMC PP Muhammadiyah" (10’)

2. "Konsep Penilaian Mandiri Bangunan Sekolah Aman Gempa" (15’)

Ir. Sri Atmaja P. Rosyidi, ST., M.Sc.Eng., PG.Cert., Ph.D., P.Eng., IPM.

Associate Professor, Prodi Teknik Sipil UMY - Divisi Organisasi dan Kepemimpinan MDMC PP Muhammadiyah.

3. “Gempa Bumi dan Problematik Bangunan Sekolah” (15')

Ir. As'at Pujiyanto, MT., IPM.

Dosen, Prodi Teknik Sipil UMY - MDMC PP Muhammadiyah.

4. "Keselamatan Bangunan Sekolah: Aspek Dokumentasi dan Tata Letak Arsitektural” (15')

Arwan Suryanto, S.T., M.Sc., IAI 
Praktisi, Akademisi dan Peneliti Sains Bangunan PUSPER UMY

5. “Diskusi (Focus Group Discussion)" (60’)

6. “Rencana Tindak Lanjut" (15')

PESERTA: MDMC PP Muhammadiyah, Majelis Dikdasmen, PWM DIY

MEDIA: Zoom Meeting

\section{WEBINAR CAPACITY BUILDING SERI 2: PENGUATAN PENGETAHUAN SEKOLAH} AMAN GEMPA: TINJUAN STRUKTUR BANGUNAN

Kerjasama MDMC PP Muhammadiyah, Prodi Teknik Sipil dan Pusat Studi Lingkungan dan Bencana (PSLB), Universitas Muhammadiyah Yogyakarta untuk Penyusunan Modul Penilaian Mandiri Bangunan Sekolah Aman Gempa

WAKTU: RABU, 12 AGUSTUS 2020, Waktu: 19.00 - 21.00 WIB

RUNDOWN:

1. "Pengantar Webinar Capacity Building Seri 2": Geo-Bencana (10')

Ir. Sri Atmaja P. Rosyidi, ST., M.Sc.Eng., PG.Cert., Ph.D., P.Eng., IPM.

Associate Professor, Prodi Teknik Sipil UMY - Divisi Organisasi dan Kepemimpinan MDMC PP Muhammadiyah.

2. "Penilaian Struktur Tahan Gempa: Aspek Desain Bangunan Sekolah" (15')

Yoga A. Harsoyo, ST., M.T.

Dosen, Prodi Teknik Sipil UMY, Tenaga Ahli Bangunan Gedung, sedang Studi S3 Manajemen Konstruksi di UNDIP

3. "Kriteria Teknis Pelaksanaan Bangunan Sekolah Tahan Gempa" (15')

Dr. Ir. Surya Budi Lesmana, ST., MT.

Dosen, Prodi Teknik Sipil UMY, Praktisi (Project Manager)

4. "Penilaian Kerusakan Bangunan Sekolah Akibat Gempa" (15')

Restu Faizah, ST, MT

Dosen (KBK Struktur), Prodi Teknik Sipil UMY, sedang studi S3 Dinamika Struktur di UGM

5. "Diskusi” (60')

PESERTA: MDMC PP Muhammadiyah, Majelis Dikdasmen PWM DIY, Kepala Sekolah/Guru Sekolah Muhammadiyah di Yogyakarta

MEDIA: Zoom Meeting 
Dari kegiatan pendampingan melalui webinar yang dilaksanakan, diperoleh sambutan dan perhatian yang dari peserta yang hadir dari MDMC seluruh Indonesia, Majelis Dikdasmen PWM DIY dan pihak sekolah-sekolah Muhammadiyah. Gambar 2 hingga Gambar 4 berikut merupakan dokumentasi pelaksanaan webinar pada kedua sesi tersebut. Beberapa bahasan penting hasil pendampingan dan perumusan tindak lanjut diuraikan berikut ini.

1. Webinar ini berangkat dari bencana gempa DIY tahun 2006 yang menyebabkan bangunanbangunan pendidikan Muhammadiyah roboh. Oleh karenanya, pembahasan mengenai penilaian bangunan menjadi hal penting dalam kegiatan pendidikan agar orang yang menitipkan anaknya di pendidikan Muhammadiyah memiliki pertimbangan tersendiri dan menilai bahwa pendidikan di Muhammadiyah tidak hanya baik secara substansial tetapi juga operasional dan sarana prasarana juga mendukung.

2. Bangunan sekolah Muhammadiyah agar dapat lebih menarik, aman dan indah bagi anak-anak dalam melaksanakan kegiatan belajar mengajar. Tiga tahun yang lalu PWM DIY membuat buku kultur standar pendidikan Muhammadiyah yang di dalamnya mengandung aspek sarana, substansi dan bangunan itu sendiri. PWM DIY sendiri menyadari bahwa masalah mendasar dalam penyediaan bangunan sekolah diantaranya terbatasnya lahan dan hal ini yang menyebabkan sekolah dibangun bertingkat dan kurang mempertimbangkan aspek aman bencana.

3. Harapan dari kegiatan ini adalah menghasilkan rekomendasi yang konkret yang kemudian dapat ditindaklanjuti oleh Majelis Dikdasmen kaitannya dengan langkah-langkah yang akan kita lakukan bersama sekolah-sekolah di Muhammadiyah utamanya yang memiliki proyeksi pengembangan.

4. Pengetahuan mengenai sekolah aman bencana sangat penting untuk meminimalisasi korban bencana karena sejatinya kita tidak pernah tahu kapan akan terjadinya bencana.

5. Daerah Istimewa Yogyakarta (DIY) merupakan salah satu daerah yang rawan terjadi bencana sehingga upaya-upaya mitigasi sangat penting untuk mempersiapkan diri.

6. Pengetahuan mengenai sekolah aman bencana merupakan keresahan kita bersama untuk dipahami dan sangat penting untuk didengar hingga ke pihak pimpinan sekolah agar urgensi penyelenggaraan sekolah yang aman bencana dapat lebih cepat disadari.

7. Kematian terbesar di gempa itu bukan karena gempanya akan tetapi dari bangunan

8. Tinjauan bangunan menjadi salah satu hal penting untuk mewaspadai dampak dari kehilangan nyawa

9. Tidak hanya struktur dari bangunan yang harus kuat akan tetapi bangunan harus juga memiliki fungsi melindungi

10. Upaya kesiapsiagaan bencana sangat penting dan diperlukan oleh karenanya kegiatan ini merupakan bagian dari upaya kita dalam kesiapsiagaan bencana. 


\section{konsep penilaian mandiri mame UMY sekolah aman gempa}

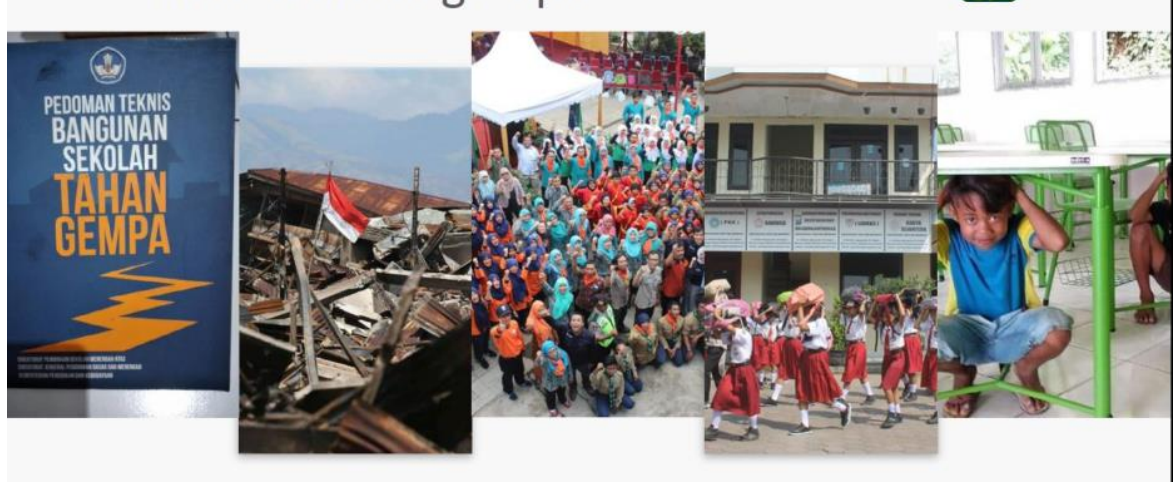

Gambar 2. Tampilan materi dalam penyampaian pendampingan melalui metode daring (webinar)

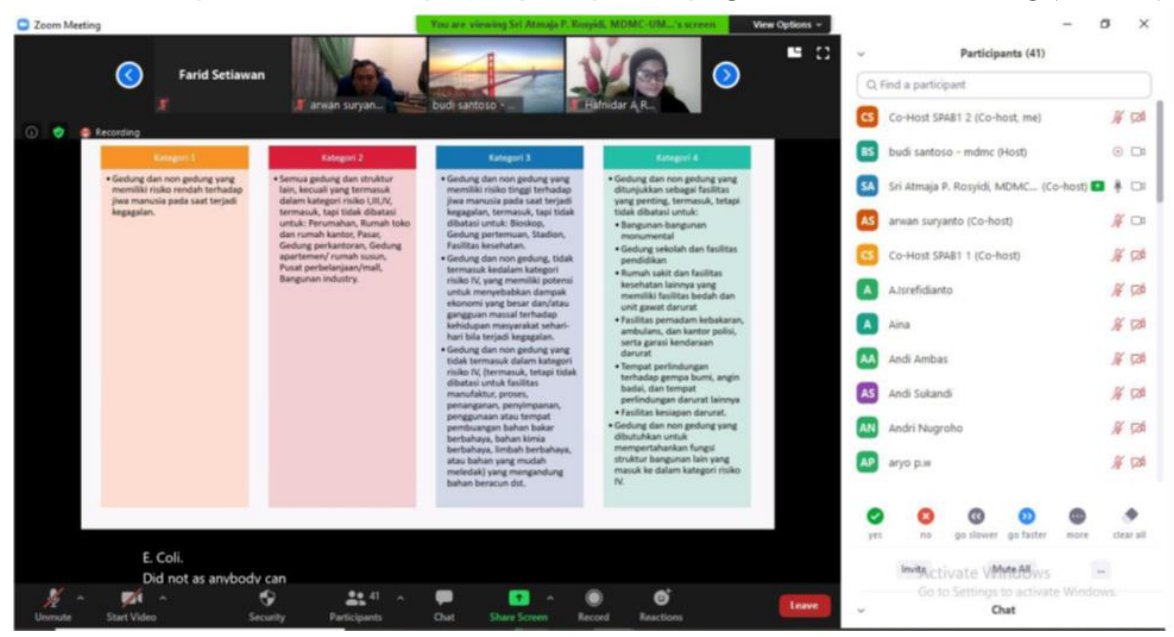

Gambar 3. Pelaksanaan webinar 1

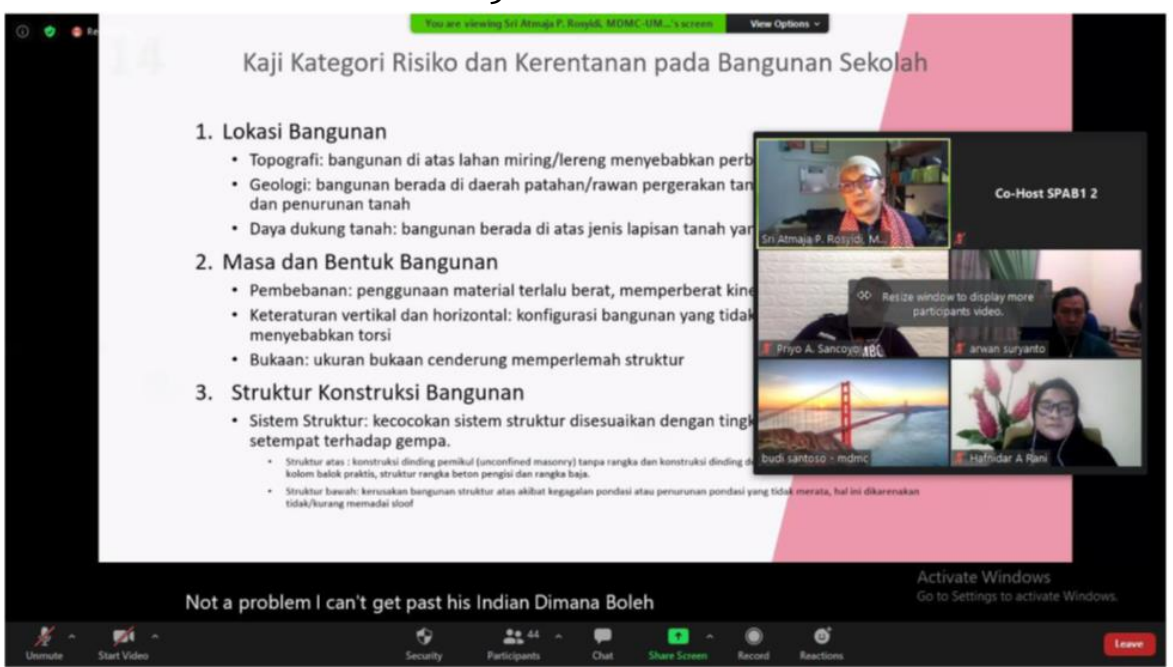

Gambar 4. Pelaksanaan webinar 2 


\section{Simpulan}

Pedoman penilaian sekolah aman bencana alam gempa bumi telah disusun dan dijadikan pedoman untuk melakukan pendampingan peningkatan kapasitas dan pemberdayaan tim evaluator sekolah aman dari MDMC PP Muhammadiyah, Majelis Dikdasmen PWM DIY dan tim penilai bangunan yang ditunjuk dari masing-masing sekolah Muhammadiyah di wilayah DIY. Pemberdayaan dilaksanakan secara daring (online) melalui seri webinar sekaligus melaksanakan penilaian sekolah yang ditunjuk untuk memperdalam materi penilaian sekolah aman secara daring diakibatkan oleh masih berlangsungnya wabah pandemi COVID-19. Kegiatan abdimas ini mendapatkan sambutan pelibatan peserta secara aktif. Pendampingan penilaian sekolah secara langsung tidak dapat dilaksanakan secara luring karena sekolah tidak dapat melaksanakan kegiatan di sekolah mengikuti keputusan PP Muhammadiyah untuk tidak melaksanakan kegiatan offline.

\section{Ucapan Terimakasih}

Terima kasih disampaikan kepada MDMC PP Muhammadiyah dan Majelis Pendidikan Dasar dan Menengah PWM Daerah Istimewa Yogyakarta yang telah memberikan kesempatan untuk melaksanakan kegiatan pengabdian masyarakat dan penyusunan pedoman penilaian mandiri bangunan sekolah aman gempa. Apresiasi serta terima kasih disampaikan kepada Zahroh Shofiyatul Fikriyah, ST, yang telah membantu dalam pelaksanaan kegiatan ini.

\section{Daftar Pustaka}

ASCE 41-13 (2014), Seismic Evaluation and Retrofit of Existing Buildings, American Society of Civil Engineers, Reston, Virginia.

Hudson, W., Hass, R., Uddin, W. (1997), Infrastructure Management, McGraw Hill.

Perka BNPB No. 4/2012 tentang Pedoman Penerapan Sekolah/Madrasah Aman Bencana.

Pujianto, A. et al. (2019), Rapid Visual Screening (RVS) for School Buildings after Earthquake in Lombok, West Nusa Tenggara, Indonesia. IOP Conf. Ser.: Mater. Sci. Eng. 650012038.

Rosyidi, SAP et al. (2008), Development of earthquake disaster management system in Bantul: Preliminary study on infrastructure damages. Proceeding the 14th World Conference on Earthquake Engineering, 12-17 October 2008 di Beijing, China.s 